\title{
Postoperative Hiccup Induced by LMA-A Case Report with Literature Review
}

\author{
C. C. Nwagwu1, L. N. Ebirim ${ }^{2 *}$ \\ ${ }^{1}$ Department of Anaesthesia, Niger Delta University Teaching Hospital, Okolobiri, Nigeria \\ ${ }^{2}$ Department of Anaesthesiology, University of Port Harcourt Teaching Hospital, Port Harcourt, Nigeria \\ Email: 'ginebirim@yahoo.com
}

Received 26 August 2014; revised 27 September 2014; accepted 11 October 2014

Copyright (C) 2014 by authors and Scientific Research Publishing Inc.

This work is licensed under the Creative Commons Attribution International License (CC BY). http://creativecommons.org/licenses/by/4.0/

(c) (i) Open Access

\begin{abstract}
Background: The laryngeal mask airway (LMA) has become popular due to simplicity of its use and its important function in difficult airway management. However, some complications have been associated with its use. A case report and review of literature on hiccups associated with the use of LMA is presented. Case Report: A 24-year-old man who presented with a right inguinoscrotal hernia was scheduled for elective surgery under general anaesthesia. He denied any co-existing medical illness. Physical examination showed a normal healthy patient and he was placed in class 1 of the American Society of Anesthesiologist (ASA) physical status category. After premedication with $0.6 \mathrm{mg}$ atropine, general anaesthesia was induced with $200 \mathrm{mg}$ of intravenous propofol. Size 5 classic LMA was inserted, and surgery had lasted for 45 minutes. He had hiccups immediately after removal of the LMA which lasted for 6 minutes, and stopped about 95 seconds after $0.6 \mathrm{mg}$ intravenous atropine was given. Conclusion: Complications from the use of LMA may be rare but still possible. It is important to adhere to the guidelines for insertion and removal of the LMA and perioperative use of the device should strictly be by trained personnel.
\end{abstract}

\section{Keywords}

Laryngeal Mask Airway, Post-Operative Hiccups

\section{Introduction}

The routine practice of airway management as a whole was changed by the introduction of the classic laryngeal mask airway (LMA) by Brain in 1983 [1]. The popularity of this airway device stems from the simplicity of its use, its important function in difficult airway management and the advantages it has over face mask and tracheal

${ }^{*}$ Corresponding author. 
tube. Although the use of LMA in general anaesthesia has an excellent safety profile comparable to other alternative airway maintenance devices [2], there are potential problems, one of which is presented here. Obstruction of the LMA by patient's bite causing a fall in arterial oxygen saturation $\left(\mathrm{SaO}_{2}\right)$ and a rise in end tidal carbon dioxide tension (ETCO2) has been observed [3]. Other complications such as coughing, retching, vomiting, excessive salivation and airway obstruction have been associated with use and removal of the LMA [4]. After LMA insertion, hiccup has been observed in $2 \%$ to $14 \%$ of patients [5].

We present a case report and a review of the literature on hiccup associated with the use of the laryngeal mask airway.

Case Report: A 24-year-old man with a right inguino-scrotal hernia was to undergo elective surgery under general anaesthesia with a classic LMA. His height was $1.65 \mathrm{~m}$ and he weighed $90 \mathrm{~kg}$. There was no history of any chronic medical illness, or previous exposure to surgery. He denied any history of cigarette smoking or use of alcohol. He had no artificial denture and there was no history of drug allergy.

Physical examination revealed a calm healthy young man with a respiratory rate of 18 breaths per minute. The breath sounds in both lung fields were normal. He had a pulse rate of 78 beats per minute and a blood pressure of 120/80 mmHg while the first and second heart sounds were normal. He was placed in American Society of Anesthesiologist (ASA) physical status class 1 and airway assessment was Mallampati 1.

His preoperative packed cell volume was $30 \%$ and urinalysis result was normal. An informed consent was obtained from the patient and he observed an overnight fast. The patient refused neuroaxial block anaesthesia and preferred to be asleep during the surgical procedure.

On arrival in the operating room, he was connected to a multi-parameter patient monitor, which showed a pulse rate of 84 beats per minute, non-invasive blood pressure of 120/70 $\mathrm{mmHg}$, an arterial oxygen saturation of $100 \%$ and a body temperature of $36.8^{\circ} \mathrm{C}$. Intravenous access was established on the left wrist with an $18 \mathrm{G}$ cannula through which an infusion of $500 \mathrm{ml}$ of $0.9 \%$ saline was commenced.

Premedication was with $0.6 \mathrm{mg}$ intravenous atropine. Oxygen was administered at a flow rate of 8 litres per minute by face-mask for 3 minutes while anaesthesia was induced with $200 \mathrm{mg}$ of propofol. With loss of verbal contact, a classic LMA size 5 was inserted and the cuff was inflated with $20 \mathrm{ml}$ of air. Anaesthesia was maintained with $2 \%$ halothane in oxygen, and ventilation was spontaneous, while intraoperative analgesia was achieved with $30 \mathrm{mg}$ of intravenous pentazocine and $30 \mathrm{mg}$ of intravenous ketorolac. The pulse rate, oxygen saturation and the non-invasive blood pressure were recorded at 5 minutes intervals during the intra-operative period. The pulse rate ranged between 78 beats/min and 84 beats/min. The oxygen saturation was between $96 \%$ and $100 \%$, while the blood pressure ranged between 70 to $82 \mathrm{~mm} \mathrm{Hg}$ diastolic and 110 to $120 \mathrm{mmHg}$ systolic.

At the end of surgery which lasted for 45 minutes, a suction catheter inserted through the mouth was used to evacuate oral and pharyngeal secretions, and administration of halothane discontinued. The patient was awake with recovered airway reflexes before the cuff was deflated and LMA was removed. The patient suddenly developed hiccups which lasted for about six minutes and stopped within 95 seconds after administration of 0.6 $\mathrm{mg}$ intravenous atropine. He was put in left lateral position, with supplemental oxygen given by nasal prongs and transferred to the recovery room for further observation. However, the hiccup did not recur for the next 5 days which he stayed in hospital before discharge.

\section{Discussion}

Hiccups consist of sudden onset of erratic diaphragmatic and intercostal muscular clonus. They occur with a sudden inspiration, immediately followed by active closure of the vocal cords leading to a hic sound [6] [7]. The hiccup reflex arc consists of three components, the afferent limb including phrenic, vagal and sympathetic (T612) nerves to convey somatic and visceral sensory signals, the central processing unit in the midbrain and the efferent limb travelling in motor fibres of phrenic nerve to diaphragm and accessory nerves to intercostal muscles respectively [6] [8] [9]. Stimulation at any of the above afferent pathways can trigger hiccups.

Hiccups that developed after inserting a laryngeal mask airway following induction of anaesthesia with propofol have been reported by many workers [10]-[12]. The stimulus for hiccups in these intraoperative settings has been attributed to LMA cuff inflation, pain at the surgical site and decreased depth of anaesthesia. The mechanism by which LMA insertion and cuff inflation triggers hiccups is considered to be due to stretching of pharyngeal mechanoreceptors, as demonstrated in cats [13] or upper oesophageal receptors, as demonstrated in humans [14]. Hiccups in this case occurred in the postoperative period just after removal of the LMA. Postopera- 
tive hiccups have been reported in subjects who underwent various surgical procedures, for example whipple operation and colectomy. Surgery-related gastroparesis was suggested as one of the mechanisms leading to the hiccups in these cases [15] [16]. Propofol induction during anaesthesia has been associated with perioperative hiccups [10] [12]. Overall, it is uncertain whether some cases of postoperative hiccups are the effect of direct surgery or secondary to anaesthetic agent [17]. Gataure et al. [4], compared 50 patients in whom LMA were removed while they were deeply anaesthetized with 50 others in whom the LMA were removed when they were awake and observed that complications during LMA removal were significantly more in the awake group. Although the listed complications did not include postoperative hiccups, but in 14 of the patients who were awake when LMA was removed, the $\mathrm{pH}$ of the secretions at the tip of the LMA was less than or equal to 3 compared with only 4 patients in the deeply anaesthetized group. This suggested a significantly greater incidence of gastroesophageal reflux in the awake group. And gastro-oesophageal reflux is an aetiological factor for hiccups [11]. They concluded that it may be safer to remove the LMA whilst the patients are deeply anaesthetized in the operating room than when they are awake often in the recovery room.

Atropine which was successfully used in this case has previously been effectively used for treatment of hiccups occurring in the intraoperative period. These hiccups followed the insertion of Laryngeal mask airway after induction of general anaesthesia with propofol [10]. Atropine could act directly on the oesophagus by means of decreasing intra-oesophageal pressure. Atropine can completely abolish the effects of muscarinic receptor agonists, which increase the tone and motility of the gastrointestinal tract and might reduce the peripheral mechanoreceptor-mediated reflex by decreasing intraoesophageal pressure. Furthermore, atropine has an indirect effect on the central nervous system through enhancement of sympathetic nerve activity [10].

Recently, Koteswara et al. in a case report noted that dexmedetomidine-a selective alpha-2 adrenergic receptor agonist abolished hiccup in a similar condition, implying that sympatholysis may have a role in suppressing intraoperative hiccup [11]. They proposed the use of dexmedetomidine instead of atropine or ephedrine which have been reported to abolish perioperative hiccups, but may cause unacceptable increases in heart rate and blood pressure [11]. However, dexmedetomidine is not readily available in many centres including ours. Metoclopramide is readily available and has also been successfully used to terminate intraoperative hiccups following LMA insertion after anaesthesia has been induced with propofol [12]. It may also be effective in abolishing hiccups occurring after removal of LMA in postoperative patients in whom anaesthesia was induced with propofol.

In the case reports on hiccups related to laryngeal mask airway insertion or removal after induction of anaesthesia with propofol, it is uncertain whether some cases of perioperative hiccups are the direct effect of surgery [17]. Injury to the delicate tissues of the upper airway during the LMA removal is a possibility in this patient that developed a postoperative hiccup. Prevention of this and other causes of postoperative morbidity associated with LMA removal is very desirable [18].

Inspite of care and best intentions, complications from the use of LMA may be rare but still possible. To avert such unpleasant scenario, it is important to adhere to the guidelines of insertion and removal of LMA and perioperative use of this device should strictly be by trained personnel.

\section{References}

[1] Brain, A.I.J. (1983) The Laryngeal Mask Airway: A New Concept in Airway Management. British Journal of Anaesthesia, 55, 801-805. http://dx.doi.org/10.1093/bja/55.8.801

[2] Brimacombe, J. (1995) The Advantages of Laryngeal Mask Airway over the Tracheal Tube or Face Mask: A MetaAnalysis. Canadian Journal of Anaesthesia, 42, 1017-1023. http://dx.doi.org/10.1007/BF03011075

[3] Umeh, B. (1996) The Laryngeal Mask Airway: A Critical Analysis of First 100 Consecutive Cases. Afr J Anaesth Intensive Care, 2, 56-63.

[4] Gataure, P.S., Latto, I.P. and Rust, S. (1995) Complications Associated with Removal of Laryngeal Mask Airway: A Comparison of Removal in Deeply Anaesthetized versus Awake Patients. Canadian Journal of Anaesthesia, 42, 11131116. http://dx.doi.org/10.1007/BF03015098

[5] Bapat, P., Joshi, R.N., Young, E. and Jago, R.H. (1996) Comparison of Propofol versus Thiopentone with Midazolam or Lidocaine to Facilitate Laryngeal Mask Insertion. Canadian Journal of Anaesthesia, 43, 564-568.

[6] Becker, D.E. (2010) Nausea, Vomiting, and Hiccups: A Review of Mechanism and Treatment. Anesthesia Progress, 57, 150-156. http://dx.doi.org/10.2344/0003-3006-57.4.150 
[7] Kumar, A. (2005) Gag Reflex for Arrest of Hiccups. Medical Hypotheses, 65, 1206. http://dx.doi.org/10.1016/j.mehy.2005.08.003

[8] Hansen, B.J. and Rosenberg, J. (1993) Persistent Postoperative Hiccups: A Review. Acta Anaesthesiologica Scandinavica, 37, 643-646. http://dx.doi.org/10.1111/j.1399-6576.1993.tb03781.X

[9] Takahashi, T., Murata, T., Omori, M., Tagaya, M. and Wada, Y. (2004) Successful Treatment of Intractable Hiccups with Serotonin (5-HT)1A Receptor Agonist. Journal of Neurology, 251, 486-487. http://dx.doi.org/10.1007/s00415-004-0377-4

[10] Kanaya, N., Nakayama, M., Kanaya, J. and Namiki, A. (2001) Atropine for the Treatment of Hiccup after Laryngeal Mask Airway Insertion. Anesthesia \& Analgesia, 92, 791-792. http://dx.doi.org/10.1097/00000539-200109000-00047

[11] Koteswara, C.M. and Dubey, J.K. (2013) Management of Laryngeal Mask Airway Induced Hiccups Using Dexmedetomedine. Indian Journal of Anaesthesia, 57, 85. http://dx.doi.org/10.4103/0019-5049.108583

[12] Pinczower, G.R. (2007) Stop These Hiccups. Anesthesiology, 104, 224.

[13] Oshima, T., Sakamoto, M. and Arita, H. (1994) Hiccuplike Response Elicited by Mechanical Stimulation of Dorsal Epipharynx of Cats. Journal of Applied Physiology, 76, 1886-1895.

[14] Fass, R., Higa, L., Kodner, A. and Mayer, E.A. (1997) Stimulus and Site Specific Induction of Hiccups in the Oesophagus of Normal Subjects. Gut, 41, 590-593. http://dx.doi.org/10.1136/gut.41.5.590

[15] Wilcox, S.K., Gary, A. and Johnson, M.J. (2009) Novel Use of Amantadine to Treat Hiccups. Journal of Pain and Symptom Management, 38, 460-465. http://dx.doi.org/10.1016/j.jpainsymman.2008.10.008

[16] Renes, S.H., van Geffen, G.J., Rettig, H.C., Gielen, M.J. and Scheffer, G.J. (2010) Ultrasound-Guided Continuous Phrenic Nerve Block for Persistent Hiccups. Regional Anesthesia and Pain Medicine, 35, 455-457. http://dx.doi.org/10.1097/AAP.0b013e3181e8536f

[17] Full-Young, C. and Ching-Liang, L. (2012) Hiccups: Mystery, Nature and Treatment. Journal of Neurogastroenterology and Motility, 18, 123-130. http://dx.doi.org/10.5056/jnm.2012.18.2.123

[18] Vaughan, R.S. (1999) The Only Man to Have All His Work Done by Friday Was Robinson Crusoe. British Journal of Anaesthesia, 82, 663-666. http://dx.doi.org/10.1093/bja/82.5.663 
Scientific Research Publishing (SCIRP) is one of the largest Open Access journal publishers. It is currently publishing more than 200 open access, online, peer-reviewed journals covering a wide range of academic disciplines. SCIRP serves the worldwide academic communities and contributes to the progress and application of science with its publication.

Other selected journals from SCIRP are listed as below. Submit your manuscript to us via either submit@scirp.org or Online Submission Portal.
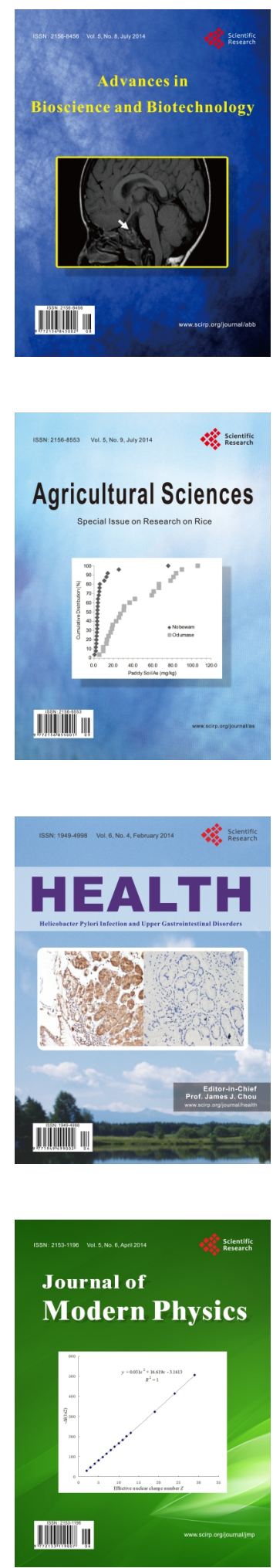
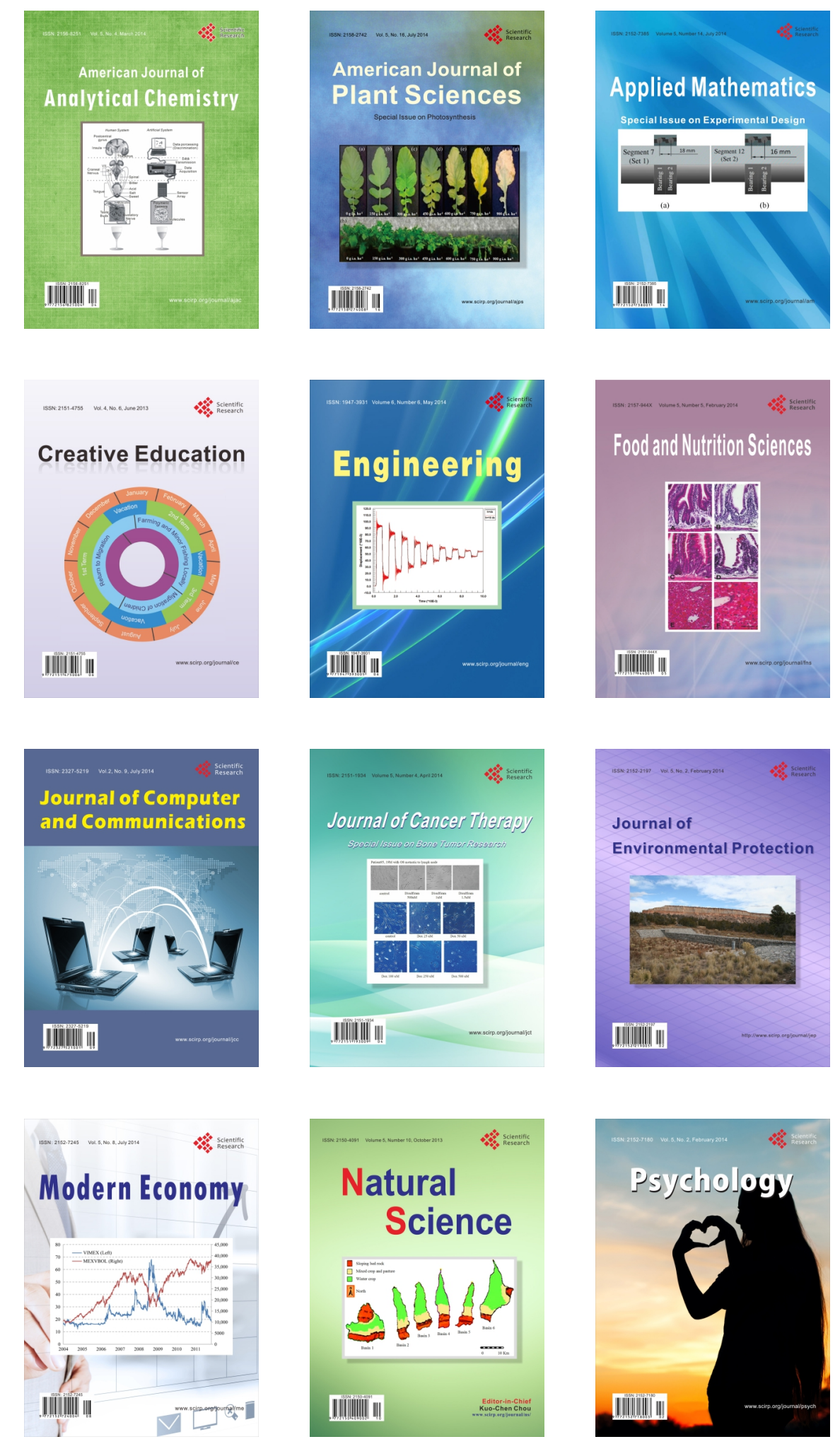